\title{
Innovative Practice of Pazeh Community Participatory Aesthetics: An Example of Pazeh Culture Travel Map
}

\author{
Hsiu Ching Laura Hsieh ${ }^{1 *}$ Chun Wei Liu ${ }^{2}$
}

\author{
${ }^{1,2}$ Department and Graduate School of Creative Design National Yunlin University of Science and Technology \\ *Corresponding author. Email:doreen850714@ gamil.com
}

\begin{abstract}
According to the field study on Pazeh community, located in Liyutan village in Miaoli County, Taiwan, it is discovered that the community presents rich ecology and landscape resources. Besides, the positive recovery of Pazeh culture in past years enhances the identity of the people and the promotion of Pazeh cultural resources expects the visitors knowing the beauty of Pazeh through the travel experience. This study, based on aesthetics and centered on Pazeh culture, aims to construct the "Pazeh culture travel map" with the participatory design process to induce design ideas through brainstorming and create the travel map design matching travel users' needs. It is expected to promote Pazeh culture assets and achieve the purpose of Pazeh cultural renaissance.
\end{abstract}

Keywords: Pazeh, participatory design, travel map

\section{INTRODUCTION}

\subsection{Research background and motive}

The Pazeh tribes in Taiwan are mainly dispersed in Liyuetan Village in Sanyi of Miaoli County, Dashe Village in Shengang of Taichung City, and Ailan of Puli Township in Nantou County. The research focused on the Pazehs in Liyuetan. The research discovered that there is a rise in the ethnic identity of the Pazehs who also started a renaissance from the bottom up, trying to resolve the predicament of passing on their culture. After actual field investigation and interviews, the Pazehs not only actively try to preserve and pass down their culture, but also actively try to promote outward the Pazeh culture, lifestyle, local tourism spots, and traditional rituals so that people will understand the tribal cultural legacy through tourism while increasing the visibility and popularity of Liyuetan community.
Therefore, the research investigated the various aspects of the Pazeh culture through the construction of the "Pazeh culture travel map". In addition, with the participatory aesthetics to undergo research, the core is that while constructing the map with the tribal people, through community participation and discussion, tribal people will be elucidated on the value of their location. They will not only gain a deeper knowledge of the land and resources, at the same time they will also achieve transmittance to the outside by self-realization and identity.

\subsection{Research goal}

The research hopes to attain the following objectives by field investigation, understanding the Pazeh community, and construction of the "Pazeh culture travel map" with the participation of the tribal people: 
1. Develop the "Pazeh culture travel map" by means of participatory designing.

2. During the process of designing with the participation by the tribal people, we hope to inspire them to seek and identify their own cultural value and the vestiges of their living environment.

3. Let tourists understand the people, sites, produce, and value system of the Pazehs through the "Pazeh culture travel map".

\section{LITERATURE REVIEW}

The research hopes to inspire the Pazeh tribal people and the tourists to value and understand the Pazeh lifestyle and cultural assets by constructing a Pazeh culture travel map in an aesthetic participation fashion. Therefore, in this part, we will explore the literatures on the Pazeh local sites and culture, and putting into practice the relational aesthetics.

\subsection{The Pazeh people, Literature, Land, Tourism}

\section{Spots, Produce}

The Pazeh community is situated in Liyuetan of Miaoli County where the mountains are pure and graceful, and the water facilities are well established that have nurtured the Pazeh, Hakka, and Minnan ethnic groups, which coexist and have co-created life appeal. The unique geographic advantage and cultural prosperity among the ethnic groups have made the Pazeh tribe one with multicultural tolerance and openness. Below are discussions on the tourism environment and ecological areas:

\section{Tourism environment}

\section{(a) Liyuetan arch bridge:}

The Liyuetan arch bridge crosses the Jingshan River valley. It is a dual track railway bridge of Taiwan Railway's mountain line that opened for traffic in September of 1998 and is the first benchmark building when entering the Liyuetan community.

(b) Neikawa iron bridge:
The Neikawa iron bridge also known as Liyuetan iron bridge, sits on the west side of the Longteng Broken Bridge and the highest iron bridge in Taiwan.

(c) Old mountain line railway:

The serial tunnels of the old mountain line railway are between Yutengping Bridge and the Neikawa Bridge for about one kilometer. It was severely damaged in the 1935 earthquake and was rebuilt as a concrete building to the present look.

(d) Liyuetan reservoir:

It is situated in Miaoli County's southeast inside Sanyi, Dahu, and Zhoulan Township and is one of the largest reservoirs in the country.

(e) Longteng broken bridge:

Longteng broken bridge, also known as Yutengping broken bridge is a building built in Japanese colonial time. It is a must-visit sight as with Shengshing Station when coming to Sanyi. It is also one of the last few existing Glutinous Rice Bridges in Taiwan.

(f) Pazeh cultural museum:

Also known as Pazeh Tribal Cultural Gathering Hall, it was established in August of 2007 and is located in the home of the director, Mr. Pan who is in charge of management. The museum exhibits many important Pazeh cultural amulets such as songs, Pazeh number culture, hunting equipment, textile, books and literature, which are all valuable cultural assets that accentuate the respect of the forefathers for ecology preservation and their wisdom on life.

(g) Liyue elementary school:

Liyue Elementary School is at the southernmost tip of Miaoli County. Since 2003, on the second Saturday of every November, the Pazeh Tribal Association holds New Year's festivities in Liyue Elementary School. The main theme centers around passing on the culture, coexistence of the ethnic groups to consolidate the tribe's people. The festivities include gong dance, Ayan singing, 'Zou Biao' 
creation to provide the audience a new experience model and the space for free imagination. Therefore, there are three ways of presenting creations in relational art :

(1) Connection and meeting : The author directly conveys the issue to the public through creation without prior warning. (2) Conviviality and encounter : Hinting the audience to feel the current social problems and predicament through artistic creation to acknowledge the situation and find solutions by self-examination.

(3) Collaborations and contracts: : The author sets the framework within which the audience can participate in order to establish interaction and finish the creation together with the audience.

Art is an activity that creates relationship in the world through symbol, format, gesture, or objects (Chen, Kuang Yi, 2014). In the process of co-creating with the Pazeh people, the research deploys the concept of relational aesthetics into the co-creation process through connecting and meeting, living and cooperating together. Using such method is nothing more than using aesthetics as a medium for producing a relationship much more realistic than creations and to incite subjective awareness in the research subjects who can then come to arrive at a new view on their own culture, living environment, and stories to achieve the goal of self-examination and identity.

\section{RESEARCH METHOD AND PROCEDURE STRUCTURE}

\subsection{The Participatory Design Method}

The meaning of participatory design method is that the users participate in the process of the design and are regarded as a 'partner' in producing the creation. Letting users provide and use their own experience during the process of design to gain first-hand user information (Wen Meng Yu, 2017) is simply design with user. The concepts of co-creation and co-design originated from participatory design. In putting 
the participatory design into practice, the researcher must set concrete goal and the format of participation plus constructing design procedure in order to achieve the core goal with the participant. The researcher also needs to be in the guidance role and lets the participant voice out through different tools to gain user experience (Mattelmäki \& Visser, 2011) and produce the research result centering around the user.

\section{3-2 Research Procedure Structure}

The research constructed the 'design procedure for creating the Pazeh culture travel map with participatory aesthetics' as in the following:

First phase, understand the people, literature, land, tourism spots, produce of the Pazeh area through exploration of literatures.

Second phase, to gain a deeper understanding of cultural evolution by field investigation, history, and status of life of the Pazeh community.
Third phase, design a 3-phase research procedure based on the result of the investigation.

Fourth phase, integrate the recommendations by the tribal people and the result of participation into the "Pazeh culture travel map"

The plausibility and efficacy of the theory on constructing the "Pazeh culture travel map" using participatory aesthetics is analyzed and discussed through the abovementioned 3-step research procedure.

\section{RECORD OF PARTICIPATORY DESIGN AND PRESENTATION OF CREATION \\ 4-1 Record of Participatory Design}

During the process of executing participatory design, the research undertook recording the project. There were three phases to the participatory design process as illustrated in table 1 , in which the content of the participatory design was also analyzed. Table two illustrates the final production of the complete travel map.

Table 1 Content of the first phase of participatory design

First phase
Location of execution Liyuetan community in Sanyi, Miaoli County, Liyuetan Church
Participants Members of the research team, Director of Pazeh community, the Pazeh people
Tools of communication Oral description of the main content, graphics and texts
The research has compiled the current predicament in promoting Pazeh cultural tourism after actual
field investigation and collection of Pazeh tribal tourist sites, ritual culture, tribal literature
information, and interviews with the tribal members. Moreover, the goal reporting the results to
the tribal members is to awaken the subjective awareness of their own culture in the members and to
understand the reason for active revival promotion of the Pazeh culture by the team.




The tourist sites categories after exploration of literature and actual field investigation.

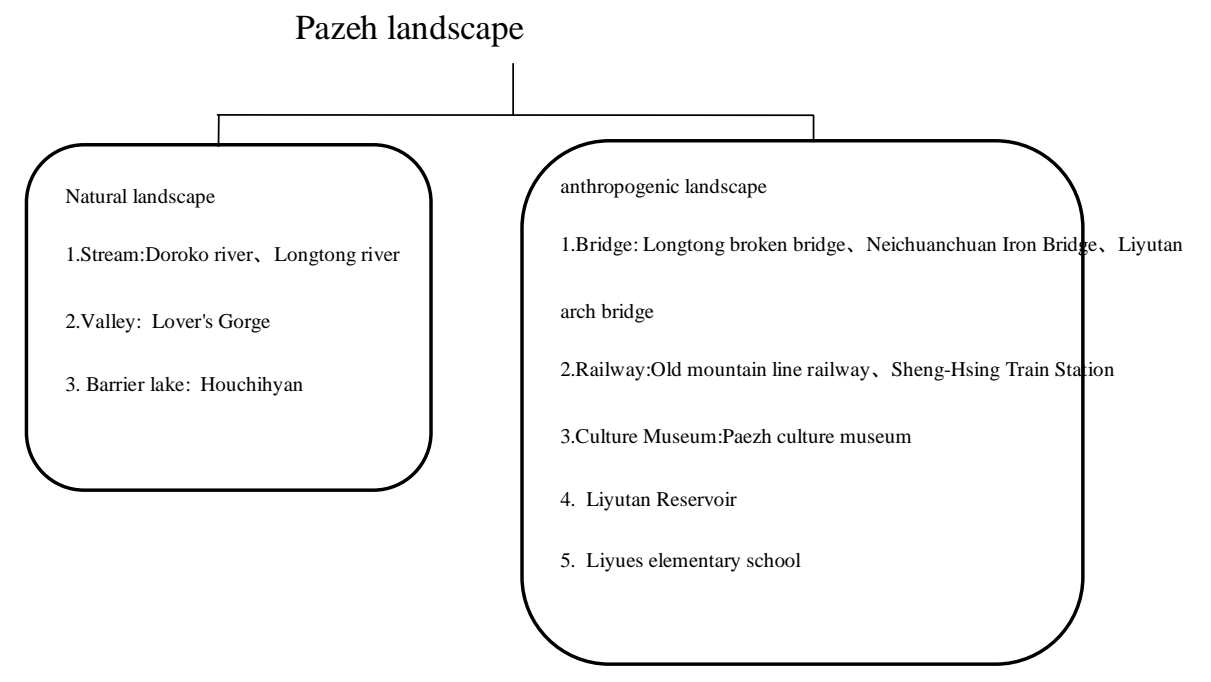

Viewpoints of the phase:

Reporting the result of the team so that the tribal members can see the beauty of the Pazeh culture through the eyes of outsiders.

Make the tribal members understand and identify with their own culture and produce collective memory through self-examination.

Based on the process design in this phase, items of discussion in the second phase

Table 2. Second phase participatory design content

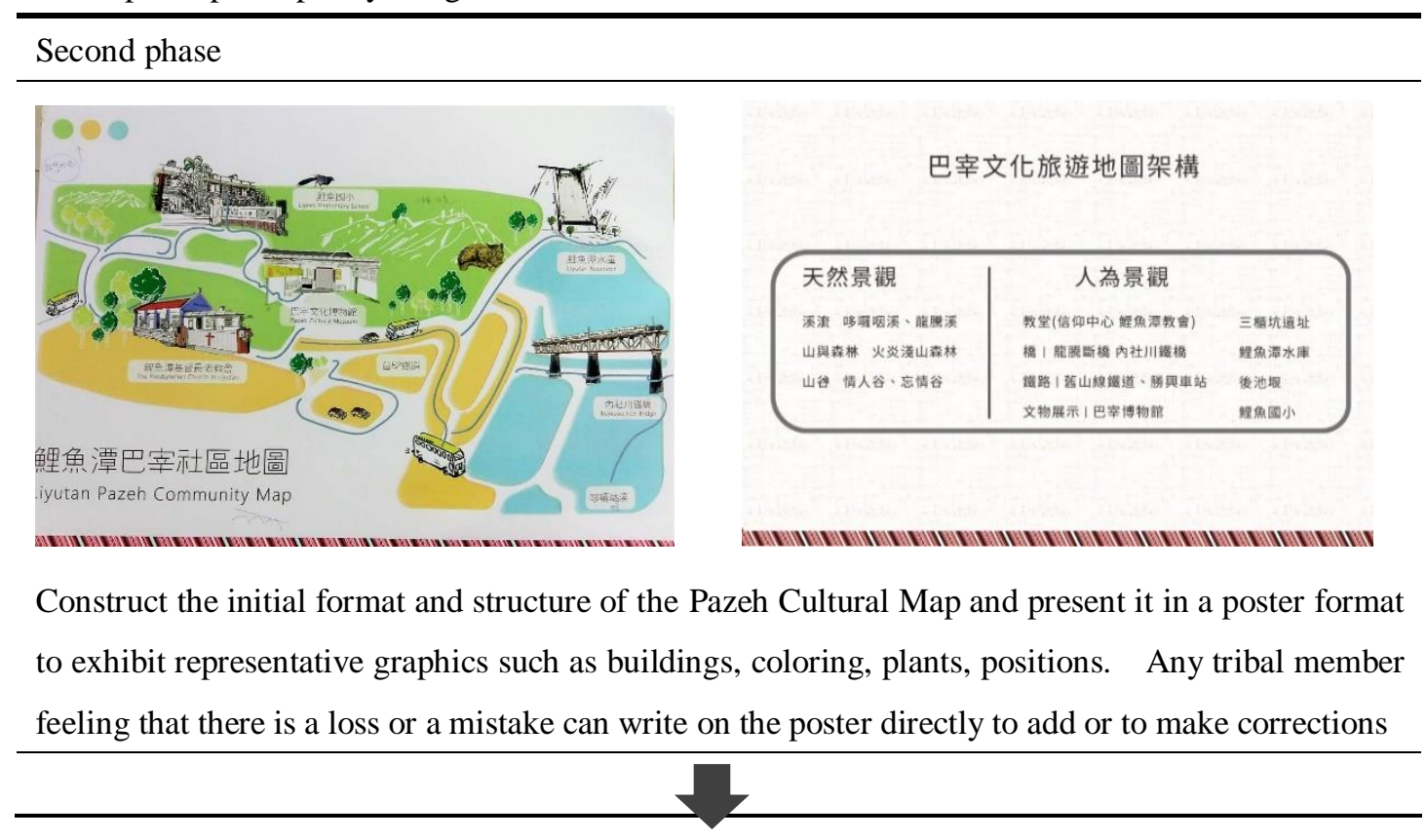




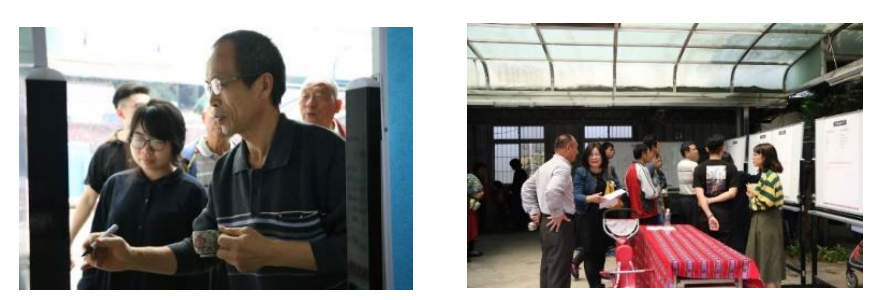

Discussion with the tribal members on the Pazeh culture travel map and its plausibility and correctness, using the poster and oral assistance to guide the tribal members to participate in the discussion and elicit their true feelings

Viewpoints of the phase:

Making corrections on the position of the buildings, revising typing errors, adding important sites

The map can appear more coordinated, coloring feels more relaxed

The style of the map was changed to that of hand drawn illustration-like feeling

Based on the process design in this phase, items of discussion in the third phase

Table 3. Third phase participatory design content



After revision based on the opinions of the tribal member in the second phase, a more complete map was produced. The tribal members participated in the discussion at the emotional level the cultural markings on the map, adding ecological species, and tribal code.

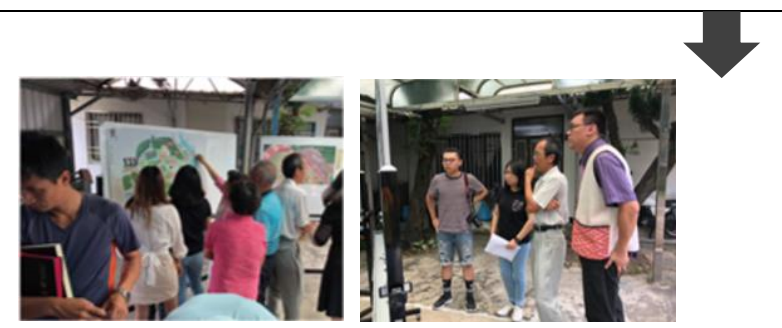

Discussion with the tribal members on the Pazeh culture travel map and its plausibility and correctness, using the poster and oral assistance to guide the tribal members to participate in the 


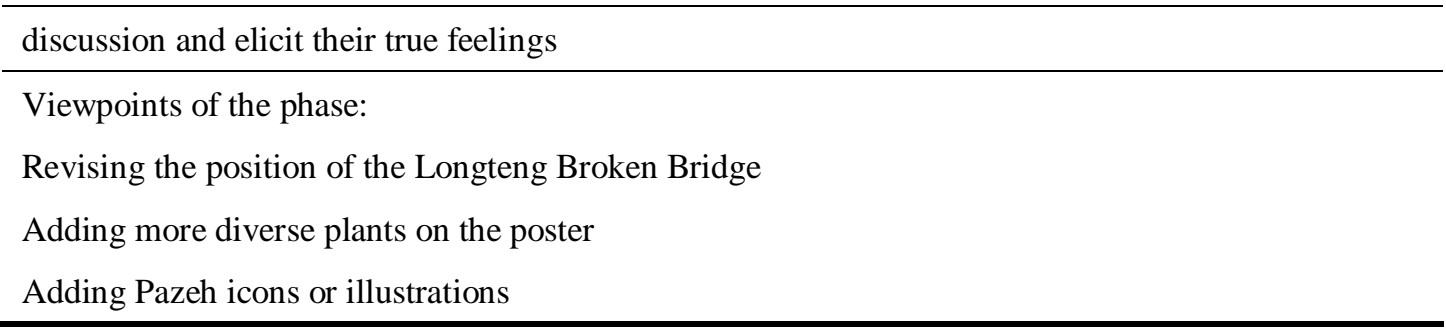

Based on the above 3 phases of participatory design process, the result of the participatory procedure is illustrated in Table 4.

Table 4 Participatory design content

\begin{tabular}{|c|c|}
\hline $\begin{array}{l}\text { Goal of } \\
\text { participation }\end{array}$ & $\begin{array}{l}\text { Problem focusing, guiding the tribal members during the process to elicit in them } \\
\text { their own identity and understanding of their own culture, guiding the community to } \\
\text { engage in dialogue }\end{array}$ \\
\hline $\begin{array}{l}\text { Communication } \\
\text { tool }\end{array}$ & $\begin{array}{l}\text { Poster (present representative graphics, stimulate memory points), oral assistance } \\
\text { (transmit emotions, create imagination space) }\end{array}$ \\
\hline $\begin{array}{l}\text { Communication } \\
\text { strategy }\end{array}$ & $\begin{array}{l}\text { Deploy guidance-type questioning to elicit thoughts in the tribal members, engage } \\
\text { in discussion and provide user experience }\end{array}$ \\
\hline
\end{tabular}

\section{4-2 Presentation of Creation}

\section{Pazeh culture travel map}

The culture travel map befitting the need of the Pazehs based on the result of the participatory design process was created as illustrated in Figure 2.

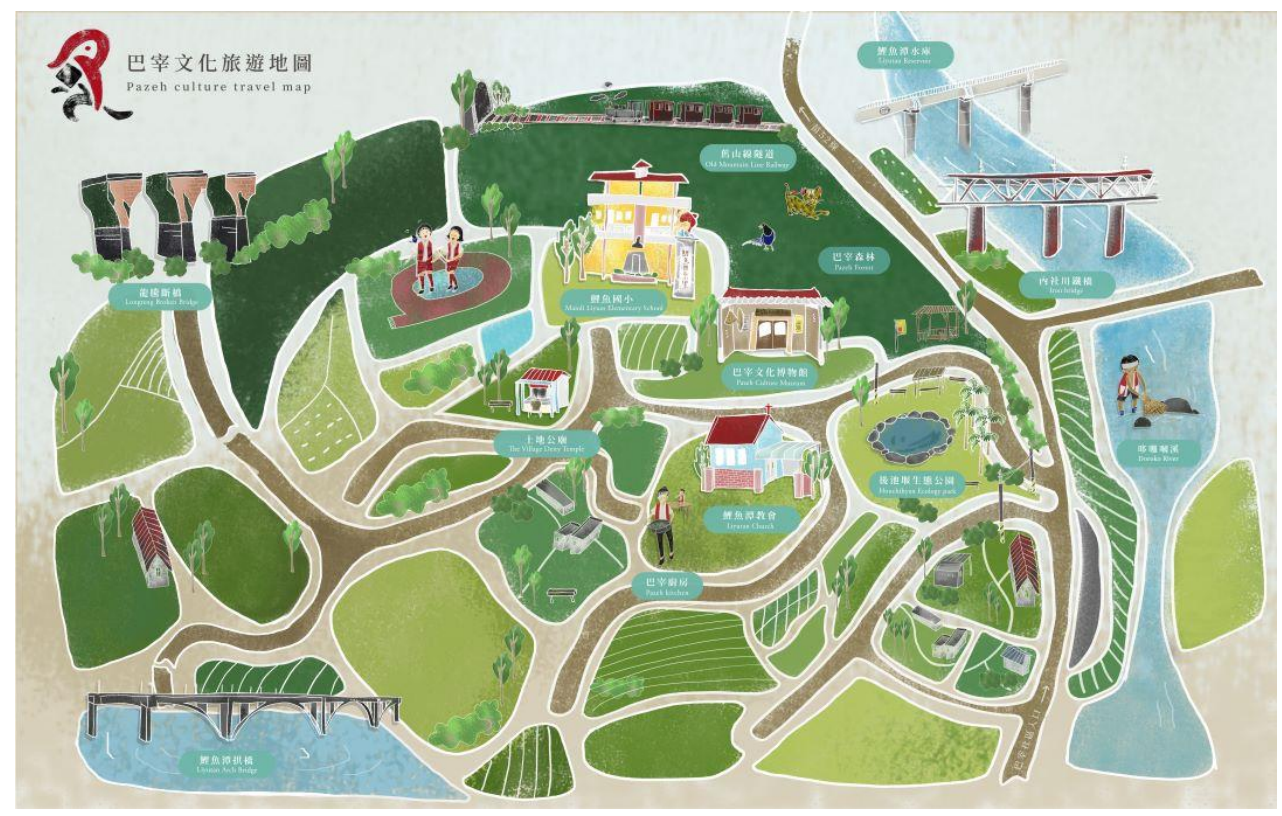

Figure 1 Pazeh culture travel map 
[2]. Huang, Chao-Mou (2014) . The Participatory Culture of Public Libraries: Referring to Digital Content Curation.Bulletin of the Taipei Public Library 32:1 2014.09[103.09] p.17-36.

[3]. Wu,Tsai-Hsuan (2017). Hakka Cuisine: inspiring the tribal members' identifying with their own culture, valuing the land resources, and creating a travel map from the viewpoint of the tribal members in order to promote the reputation and visibility of the Pazeh community during the process of producing the Pazeh culture travel map together with the tribal members are achieved. The process of the research collected the most realistic outtake on the tribal culture and environment which were transformed into the map. As for leading the tourists who read the map to get to know the unique culture, tourist sites, produce, and value of the Pazeh community in order to effectively enhance the tourist's user experience, knowledge of the Pazeh culture, more needs to be done by visiting the Pazeh tribe and user evaluation in the future.

\section{REFERENCES}

[1]. Chen, Kuang-Yi (2014).The Production of Theory in the Biennial's Curatorial Mechanism.Modern Art.175.6-15. Relational Aesthetics as An Art Education Practice. Taipei National University of the Arts master's thesis. Taipei City.

[4]. Li, Chia-Ying (2015). Research on Art Presentation of Relational Aesthetics in Taipei Biennial 2014.National Taiwan Normal University Department of Graphic Arts Communication master's thesis. Taipei City.

[5]. Wun, Meng-Yu (2017).An Analysis Study of a Participatory Design Workshop: From the Perspectives of Communication Strategies and Tools.National ChiaoTung University The Department of Communication and Technology master's thesis. Hsinchu, Taiwan.

[6]. Yu-Chi Tsai (2013). Usability Evaluation of Thematic Web Mapping. National Taiwan University Department of Geography .Taipei City 